diathermy. He was seen again on December 2, 1946, the evening before operation, when the cyst was found to be more than double its original size. The next day, immediately before operation, a final ophthalmoscopic examination was made, and in place of the cyst a dialysis was seen occupying an area exactly corresponding to that previously occupied by the cyst, associated with a shallow detachment of the retina running a considerable way towards the disc. Diathermic coagulation was performed with a satisfactory result; six months later the retina was completely re-apposed and the vision was $6 / 5$.

\title{
FACULTY OF OPHTHALMOLOGISTS
}

The following is the Honorary Secretary's summary of the business conducted at the last Council meeting on April 29:-

The following were elected Officers for 1949-50:-

President : Mr. Frank W. Law ; Vice-President : Mr. J. J. Healy ; Honorary Secretary: Mr. J. H. Doggart ; Honorary Treasurer : Mr. A. B. Nutt.

It was reported that Dr. Charles Hill had written to the Ministry of Health protesting against the reduction in fee for work under the Supplementary Ophthalmic Service. It was also reported that a letter had been received from the Ministry of Health, stating that $\mathrm{Mr}$. W. Penman was, willing to undertake an investigation of the average time taken for a sight-test, and asking the Faculty to nominate four members to be associated with him as an informal working party to watch the investigation and study the results. Mr. Black, Mr. Healy, Mr. Gayer Morgan and Mr. Simpson have been nominated to represent both the Ophthalmic Group Committee of the British Medical Association and the Faculty.

It was learnt that the practice of referring patients from the hospital clinics to the Supplementary Ophthalmic Service did not meet with the approval of the authorities. It was agreed to write to the Ministry stating that the Faculty did not approve of this practice, but until more assistance, technically and financially, was received towards the progress of the Permanent Service there did not appear to be any alternative. It was also decided to point out that the prescriptions of the patients seen in Hospital must be made up in the Hospital ; otherwise there would be no saving financially.

The draft handbook for ophthalmic medical practitioners and ophthalmic opticians, together with the comments of the Ophthalmic Group Committee, was considered. The Ophthalmic Group. Committee's comments were approved, but it was felt that it should 
be illegal for an optician to prescribe glasses for any case which had been referred back to the general practitioner. It was decided to recommend to the Ophthalmic Group Committee that representa. tives from the Committee and the Faculty should discuss this point with the Ministry, and the Chairman of the Group Committee and Mr. Law were nominated to act in this capacity.

At the suggestion of the Ministry, of Health a Committee of Referees is to be set up to deal with matters arising from the regulations governing the working of the Supplementary Ophthalmic Service.

A letter was received enquiring whether a spare pair of glasses should be issued to cover the risk of breakage. It was reported that this had been referred to the Ministry of Health, who had replied that under the Supplementary Ophthalmic Service and the Hospital Eye Service a patient was not entitled to glasses if already in possession of a pair.

It was reported that a letter received from a member regarding domiciliary visits had been referred to the Ministry of Health, who had replied that if the Supplementary Service was used for bedridden patients the ophthalmic medical practitioner or ophthalmic optician could, if he wished, ask the patient for a reasonable fee for visiting him instead of the patient attending his consulting rooms. The Ministry felt, however, that all bedridden cases should be brought under the Hospital Eye Service and not the Supplementary Service.

It was agreed to call a meeting, consisting of the Officers of the Faculty and the Ophthalmic Advisors to the Regional Hospital Boards, to consider points in connection with the Permanent Service.

It was learnt that, in spite of protests from the Faculty, the Ministry of Labour and National Service had decided to reduce the fee payable to ophthalmic medical practitioners for sight tests made on and after April 1st, 1949, under the National Health Service from $£ 1.11 \mathrm{~s} .6 \mathrm{~d}$. to $£ 1.5 \mathrm{~s} .0 \mathrm{~d}$.

A request from the Joint Committee for Consultants to draw up criteria for consultants and specialists for the specific purpose of assisting those considering appeals from the decisions of the Review Committees was considered. After discussion, it was agreed to submit the following recommendations :-

1. Consultants should have ten years' approved training and experience in ophthalmology in all its branches after qualification.

2. Consultants must hold a higher degree or diploma.

3. Consultants must hold or have held a recognised appointment to a hospital.

A letter was read from the Ministry of Health giving the terms of reference and constitution of the proposed Committee on the 
registration of opticians. The suggested terms of reference were "on the assumption that it would be to the public interest that provision should be made by legislation for the registration of opticians, to advise how registration could best be carried out, and what qualifications should be required as a condition of registration." The Ministry suggested that the Committee should consist of twelve members under a lay chairman to be appointed by the Minister, the members consisting of 3 ophthalmologists (1 from Scotland), 1 physician, 1 physiologist -4 ophthalmic opticians ( 1 from Scotland), 1 dispensing optician -1 physicist and 1 Member of Parliament (neither medical nor optical). The Faculty was asked to submit nominations for the first group. Though it was felt that ophthalmology was not adequately represented, it was agreed to submit nominations jointly with the Ophthalmic Group Committee. of the B.M.A.

- The recommendations made by the Joint Advisory Board of the Optical Profession to the Examining Bodies on the training and examination of future entrants to the optical profession were considered. It was decided :-

(a) That the General Anatomy and Physiology section was too detailed. .

(b) To ask for further information regarding the examination in the use of drugs.

(c) That the section dealing with Abnormal Ocular Conditions in the syllabus and in the examination should be deleted. It was agreed that opticians who worked in hospitals would have an opportunity for practical experience in recognising diseases, but that this should not form part of the qualifying examination.

The question of lecturing to opticians again arose. Although the Council felt that there was no objection to members giving an occasional lecture on an optical or medico-political subject, it was agreed that a final decision could not be made until the report had been received from the Commission on the registration of opticians.

A memorandum on the practice of orthoptics has been prepared and will shortly be published in the British Medical Journal.

Regarding the proposed changes in the system of the training of nurses, it was decided to ask Mr. Law to approach the ophthalmic matrons to enquire what action had been taken, and to raise the matter with the Royal College of Nursing.

It was realised that the Regional representation on the Council left something to be desired, and letters pointing this out had been received by the Honorary Secretary. It was finally decided to alter the regions to correspond with those defined under the National Health Service. The Council will be reconstituted as follows :- 
(a) One Member elected from each Region under the National Health Service (14).

(b) One Member from Scotland.

(c) One Member from Northern Ireland.

(d) One National representative from the Full and Part-time Associates.

(e) Eight National Member representatives.

Such an arrangement, would leave its total number unchanged.

\section{BOOK NOTICES}

The Management of Binocular Imbalance. By E. KRIMSKY (New York). 464 pages, 200 figs. Henry Kimpton (London), 1948. Price 63/-.

A number of books on the ocular muscles and the problems of their imbalance have appeared in recent years, but this volume has the very considerable merits of being at once.interesting and stimulating. It takes as its text the corneal reflex, and shows how this can be exploited by means of the simple equipment of a flash-light and prism to form the basis of an extremely complete objective and subjective analysis of the binocular function and state of motility. The corneal light reflex has, of course, been employed for many years by such investigators as Hirschberg, v. Graefe, Priestley Smith, Tscherning, Landolt and innumerable others in the investigation of squint, but no one has yet attempted so thorough an exploitation of its potentialities as to include not only an examination of monocular and binocular fixation, the angle of latent and manifest deviation in squint, but also, among other things, the measurement of the depth and area of suppression in a deviating eye, the elicitation and location of abnormal correspondences and false projection, the proof of the existence of diplopia and the analysis of head-tilt. The theory of the method is well-known : the corneal "reflex" is an erect virtual image formed behind the cornea which in the normally fixing eye occupies a " neutral" position centrally (apart from the angle gamma) in the pupillary area; on the displacement of the eye out of the normal position of fixation, the reflex is also displaced, and can be restored to the neutral position by placing the appropriate prism in the required position in front of the cornea. Latent deviation can similarly be estimated by dissociating the two eyes with a prism 